\title{
Italian women meet glass ceiling in the lab
}

Alison Abbott

Men are three times more likely than women to be promoted to top positions in Italian publicly funded research laboratories, according to a study to be released early in the new year.

The study also finds that $90 \%$ of institute directors are male. Men even hold many of the top positions in disciplines where women form the majority of junior researchers, such as biology and the social sciences.

The study was conducted by a working group of senior women scientists, with the backing of Italy's National Research Council (CNR). It was chaired by Rossella Palomba, director of the CNR Institute for Population Research in Rome. Data were analysed from 15,000 publications and from the archives of hundreds of public research institutes, employing 7,000 scientists.

Palomba says that Italy is probably not the worst performer in Europe, but that the study's findings are still shocking.

"The difference in career opportunities for women in research in Italy cannot be explained by the difference in the number of publications," she says. On average, men publish under one paper per year more

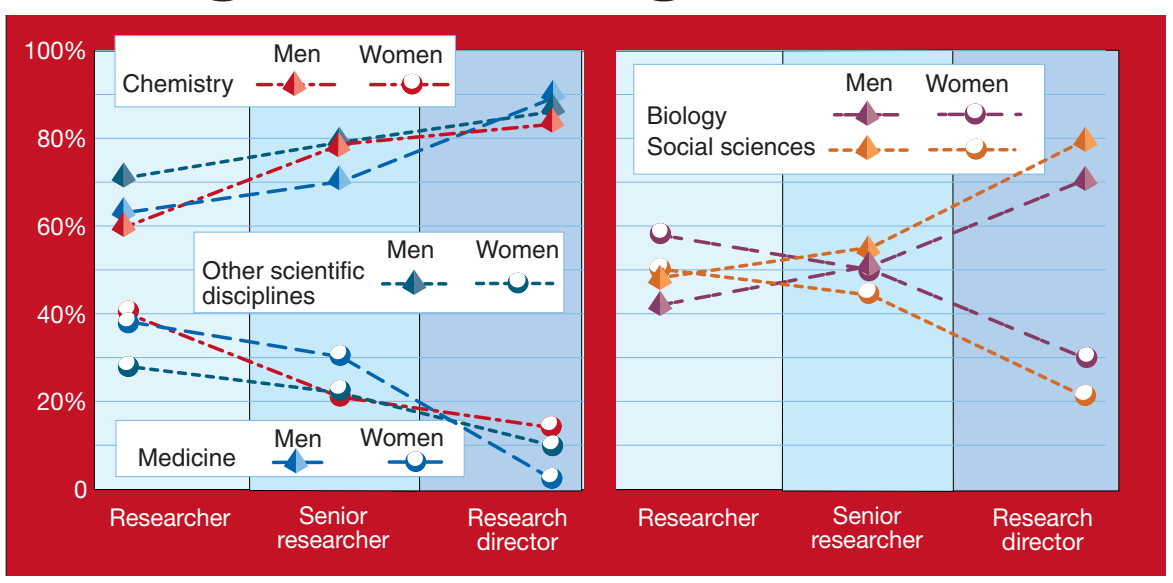

Gender issues: how women's careers take a turn for the worse.

than women, she explains. But a bigger publication gap comes between the ages of 35 and 39, at a time when women are often involved in child care and men are busy getting promoted.

Many of the more successful women researchers forgo the opportunity to have children, the study finds. Nearly $40 \%$ of female research directors are childless, as are $22 \%$ of senior researchers.

Palomba suggests that the situation might be improved if more women sat on selection panels, and if institutes were asked to publish the number of women on such panels. "Merely publishing gender statistics will probably make a difference," she says. "And having women on the panels will help break up the old-boy networks that cause women to be overlooked."

But Enzo Iarocci, president of the National Institute of Nuclear Physics (INFN), says that there are so few women in 
top positions that gender correction on committees is not feasible.

"I was shocked to realize that there is a factor-of-ten loss between women who join INFN at the lowest rank and those at the top," he says. He sees no obvious solution, but says the INFN is "open to all suggestions".

One concept that finds no favour is the introduction of quotas of senior slots for women scientists. "We don't want a quota for women," says Flavia Zucco, a senior researcher at the CNR Institute for Biotechnology Research in Rome. "We just want the quota for men abolished."

The findings were welcomed by European Research Commissioner Philippe Busquin, who said the study was "the first to undertake a full comparative analysis of women's careers in public research institutes". Lack of data on women's careers in research hinders attempts to resolve the problem, according to Busquin.

Mary Osborn, a researcher at the Max Planck Institute for Biophysical Chemistry in Göttingen, Germany, who helped produce the European Commission's recent report on women and science (see Nature 402, 337; 1999), sees "no single solution to the problem". She argues that the issue needs to be "tackled by all means and at all levels".

Another investigation of women's careers in Italian universities is about to start.

\section{International search underway in Italy for institute directors}

Italy's National Research Council (CNR) is this week breaking from its much-criticized practice of filling key posts from within its ranks, and is advertising internationally for scientists to head some of its institutes.

The positions are the first to arise under a reorganization that will combine some 300 CNR institutes and university-based centres into 95 larger units. This is the first step in a reform programme to make the CNR more efficient (see Nature 394, 712; 1998).

The appointments are for four-year renewable terms. Each new director will be responsible for coordinating research programmes at the merged centres and institutes.

Most scientists agree that the new arrangement will promote collaborative research, but say that, with no extra money available for research, it is not ideal.

Some observers are also sceptical about whether outsiders will find the new directorships attractive. For example, they will have few opportunities to build their own research teams. This is "a weakness in the process", says John Guardiola, head of

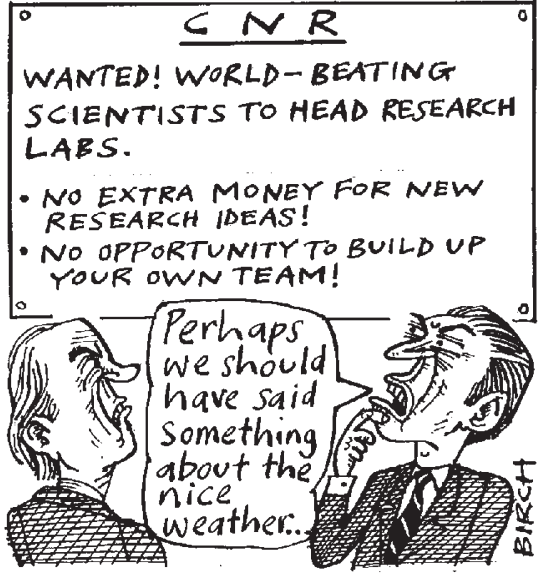

the CNR International Institute of Genetics and Biophysics in Naples.

Arturo Falaschi, the director of the International Centre for Genetic Engineering and Biotechnology in Trieste, is more optimistic. Together with an expected competition to attract 1,000 researchers, he says advertising the directorships could help to address problems such as gender imbalance. 